\title{
Supply Chain Finance: Modelling a Dynamic Discounting Programme
}

\author{
Luca M. Gelsomino, Riccardo Mangiaracina, Alessandro Perego, and Angela Tumino \\ Politecnico di Milano, Department of Management, Economics, and Industrial Engineering, Milan, Italy \\ Email: \{lucamattia.gelsomino, riccardo.mangiaracina, alessandro.perego, angela.tumino\} @ polimi.it
}

\begin{abstract}
In the last 10 years, new financing opportunities (known as "Supply Chain Finance" or SCF) arose, exploiting the strength of new ICTs and supply chain links to optimise the working capital and create value for the organisations involved. One of the solutions within the SCF landscape, called Dynamic Discounting (DD), utilises trade process visibility granted by an ICT platform to allow the dynamic settlement of invoices in a buyer-supplier relation: for every day of payment in advance with respect to a predefined baseline, the supplier grants to the buyer a discount on the invoice nominal value. DD is a supply management tool for which a cash-rich anchor buyer can let suppliers (especially SMEs) fast-access cash, while gaining a relatively high rate of return. This paper aims to estimate, through the development of an analytical model, the potential benefit sof using a DD model in a buyer-supplier relation. After a brief review of relevant literature, the paper presents amodel that compares, for the supplier, the cost of granting a discount to the buyer with the benefit of an early payment, whereas for the buyer, the benefit of receiving a discount with the financial cost of an early settlement. This paper fills the gap in literature related to the definition of the processes underlying the adoption of DD, and more broadly the need for models to assess the benefits of the most innovative SCF schemas.
\end{abstract}

Index Terms-dynamic discounting, supply chain finance, working capital, supply chain management

\section{INTRODUCTION}

The recent economic downturn caused a considerable reduction in the granting of new loans, with a significant increase in the cost of corporate borrowing [1]. In these difficult times, firms tried to extend trade credit from suppliers in order to supplement other forms of financing, whereas organisations less affected by this credit crunch took the role of liquidity providers, accepting an increase in payment terms [2]-[3]. These effects contributed considerably to the need for solutions and programmes that optimise the working capital. Among these, one of the most important approaches is Supply Chain Finance (SCF) [4]. SCF aims to optimise financial flows at an inter-organisational level [5] through solutions implemented by financial institutions [6] or technology providers [7]. The ultimate objective is to align financial flows with product and information flows within the supply chain, improving cash flow management from a

Manuscript received November 10, 2014; revised January 13, 2015. supply chain perspective [8]. The benefits of the SCF approach rely on the cooperation among players within the supply chain, which typically results in lower debt costs, new opportunities for obtaining loans (especially for 'weak' supply chain players), or reduced working capital within the supply chain. Moreover, the SCF approach often improves trust, commitment, and profitability throughout the chain [9].

One of the most innovative SCF solutions, called Dynamic Discounting (DD), utilises trade process visibility granted by an ICT platform to allow the dynamic settlement of invoices in a buyer-supplier relation: for every day of payment in advance with respect to a pre-defined baseline, the supplier grants to the buyer a discount on the invoice nominal value. Therefore, the buyer profits from a discount, whereas the supplier profits from an early payment. DD, respect to common form of trade credit, allows an invoice-byinvoice settlement of invoices, with enhanced mutual benefit with respect to well-known trade credit methods [4], [10].

The model presented in this paper aims to overcome some of the gaps and limitations stemming from the literature analysis by assessing the benefits that could be achieved with the systematic implementation of a DD programme. The paper is organised as follow: next section briefly summarises the literature, whereas the remaining sections present the objectives and methodologies, the analytical model developed, a case study and, finally, some conclusions and insights for future research.

\section{LITERATURE REVIEW}

This section firstly reviews the concept of SCF, which encompasses DD, then focuses on trade credit and its relation to $\mathrm{DD}$.

\section{A. Supply Chain Finance}

Supply Chain Finance has been defined in many ways: as a set of financial solutions [6], [11], as an advanced form of Reverse Factoring [8], or, more broadly, as the inter-company integration and optimisation of financial processes in the supply chain [12].

Starting from the point of view of [12], for the scope of this paper, SCF can be defined as a mix of models, solutions, and services aiming to both optimise the financial performance and control working capital within 
a supply chain, exploiting a deep knowledge of supply chain relations and dynamics.

Although some literature contributions state that the focus on SCF is on the optimisation of account receivables and payables only [6]-[7], the supply chain perspective on SCF taken in this article expands such focus also to collaborative inventory optimisation to reduce working capital needs. Many authors share this perspective. As a way of example, some authors state how their conceptual SCF model has been tested in a VMI scenario[12], whereas others simply analyse the benefits of a generic shifting of inventory among two supply chain players[9]. Moreover, some of the contributions on the topic expand the focus of SCF even beyond working capital, stating that SCF applies also to fixed assets financing, e.g.: through pay per production solutions or joint investment decisions in logistics assets [5], [12]-[13].

One of the most important existing gap in SCF literature is the lack of models that assess the benefits of the different SCF solutions, especially those regarding the more innovative ones [14]-[15].

\section{B. From Trade Credit to Dynamic Discounting}

Dynamic Discounting takes root from the cashdiscount policy typical of trade credit practices and, through a proper use of a buyer-supplier integrated platform, allows the dynamic settlement of invoices [10].

Trade credit can be defined as a short term business loan from a supplier that finances the purchase allowing the buyer to delay payment [16].Contributions focused on trade credit are plentiful [17]-[19]. Specifically, they can be divided into seven groups: monetary policy implications, credit risk models, trade credit motives, order quantity decisions, factoring economics, credit term decisions, and settlement period decisions [18].It is recognised that the concept of trade credit is strictly related to SCF [20]-[21]. Trade credit is one of the most used sources of liquidity by firms. In many countries, notably the USA, it is used in two basic forms: a simple delay in payment, or a two-part term policy (also known as cash discount policy), in which the supplier allows the buyer to settle payment within a short term (e.g. 10 days) in exchange for a discount (e.g. $2 \%$ ), or within standard payment terms for the total nominal value [16].

With regard to $\mathrm{DD}$, it is considered one of the most sophisticated SCF techniques and one of the most important recent trends in treasury and supply management. It is one of the most important "threecorner" SCF models (i.e. models that involve a buyer, a supplier and a third party, which can be a financial institution or an IT service provider), and a common schema that lets SMEs, suppliers of an anchor buyer, fast access cash at acceptable rates[4], [10], [22].

DD is believed to reduce uncertainty in working capital needs, thus allowing suppliers to better plan cash flow in. From the buyer point of view, DD generally grants the best rate of return in today's markets [4]. The programme reduces also trade process uncertainty. However, to properly function, it requires a cash-rich buyer, and the need to manage different platforms might discourage a SMEs from using the programme with multiple buyers [22].

DD has also received great attention from practitioners. Recent market analyses, focused on SCF, devote considerable attention to this programme and to the providers that offer it [23]-[24].

Although the interest in the topic seems to be high, both from a practitioner and academic point of view, no attempts have been done so far neither to define a reference process nor to model its benefits.

\section{OBJECTIVES AND MethodologIES}

The model presented in this paper aims to overcome some of the gaps and limitations stemming from the literature analysis by assessing the tangible benefits (i.e. differential profit) that could be achieved by a buyersupplier dyad with the systematic implementation of a (DD) programme.

Starting from the aforementioned objective, the following research questions have been identified:

$R Q 1$ : how can a generic DD process be modelled?

$R Q 2$ : how can the tangible benefits of a systematic use of the DD programme within a buyer-supplier dyad be assessed?

The model has been developed and applied according to a three-phase methodology. In the first phase the definition of the reference process either with or without the DD settlement solution was performed. Two main sources were adopted: a literature review on the structure of the invoice settlement process, and interviews with treasurers, CFOs, and CPOs from four large companies. The outcome of this first phase lied in the identification of three main macro-activities with regard to the base case process: Invoice uploading, Invoice receiving, and Invoice archiving. With regard to the DD case, a phase named Early Payment Proposal issuing is added between the Invoice receiving and the Invoice archiving. The processes are presented in Section IV.

The second phase consisted in modelling the tangible benefits of DD - in terms of expected profit for the buyer and the supplier - assessing the differential benefits of the systematic use of DD with respect to the base case. Three main sources were used: (i) a literature review on the trade process and trade credit modelling; (ii) interviews conducted with the aforementioned four companies in order to collect detailed information on the activities related to the trade process and affected by the DD programme; (iii) analysis of secondary sources, such as studies or reports that detail DD programmes, its working mechanisms and other relevant information, such as forms of revenues commonly implemented by service providers [23]. The outcome of this phase was: (i) the modelling of the profit for the buyer and the supplier, using a discrete-event analytical modelling approach, coherently with literature related to trade credit in the supply chain [25]-[26]; (ii) the determination of the inputs and the context data required to run the model. The detailed description of the model is reported in Section V.

In the third phase a case study has been developed, reflecting data collected through interviews. A sensitivity 
analysis has been performed on the results, varying some key parameters.

The analytical approach used to model benefits has been chosen in order to develop a model with general validity (i.e. changes and modifications can be applied to each single modelled activity with a limited effort) and transparency (i.e. hypotheses are clear and evident from the equations).

\section{THE REFERENCE PROCESS}

In this section, first of all, the base case process is presented; secondly, the DD is introduced within such process.

Given a generic invoice, issued by the supplier and referring to one or more goods shipped/services provided, the base case process (represented in Fig. 2) is fairly straightforward. Coherently with the literature [27] it has been structured in three main phases:

- Invoice upload.

It includes all the activities carried out by the buyer in the process of issuing the invoice. It involves the buyer only. The process starts with the composition of the invoice. Invoices are exchanged between the buyer and the supplier electronically, e.g. through Electronic Data Interchange (EDI) communication systems. The phase ends when the e-invoice is sent to the buyer (e.g. uploaded on a platform or portal). It is assumed that the goods (services) invoiced have already been shipped (performed) before this phase begins.

- Invoice receiving.

It includes all the activities carried out by the buyer after receiving the invoice (i.e. after the uploading on the platform). It involves the buyer only. The process ends with the approval for payment.

- Invoice archiving.

After the invoice has been sent (bythe supplier) and has been received and registered (bythe buyer), both the supplier and the buyer electronically archive it.

The DD process differs from the base case process because of the possibility for the buyer and the supplier to exchange an Early Payment Proposal (EPP). An EPP is a request for an early settlement of an invoice, in exchange for a discount on the nominal value (i.e. face value) of the invoice. An EPP is defined by two pieces of information: (i) the day in which the payment is going to be settled and (ii) the discount proposed for such early payment with respect to contractual terms. For example, an EPP related to an invoice due the $31^{\text {st }}$ of March might be defined as: [11 ${ }^{\text {th }}$ of March; $0.4 \%$ ], meaning that the issuing party (generally the buyer) proposes a settlement 20 days early with respect to contractual terms, with a $0.4 \%$ discount on the invoice nominal value (equal to a $0.02 \%$ per day times 20 days).

As represented in Fig. 1, assuming that the daily discount rate does not vary, a generic EPP can be interpreted in terms of a negatively sloped straight line: the highest discount occurs in case of "cash in hand" payments (payment upon invoice receiving), while if the payment occurs at contractual payment terms no discount is applied. The slope of the line represents the discount (in terms of percentage per day) granted by the supplier for a day of payment in advance with respect to the baseline. In this example, it is assumed to be constant, while in different configurations it may be decreasing with respect to time, in order to encourage earlier payments.

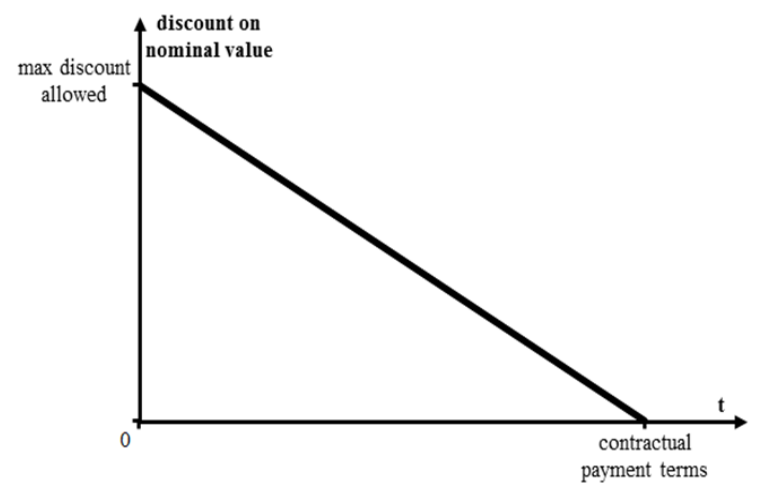

Figure 1. A generic dynamic discounting programme with constant daily discount rate

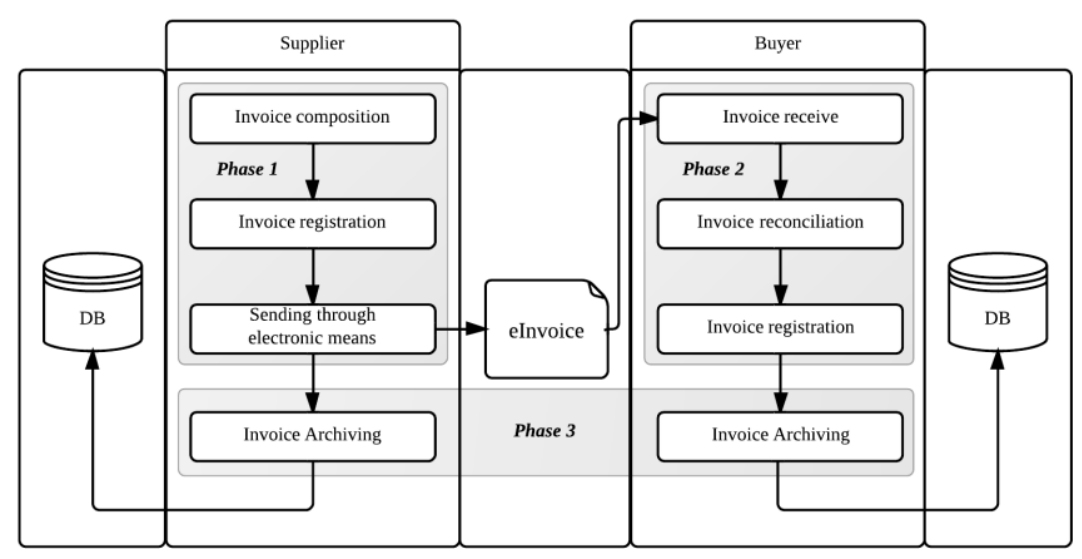

Figure 2. The base case reference process 
The DD process, represented in Fig. 3, has been structured in fourphases:

- Invoice uploading and Invoice receiving.

These two phases do not present any particular changes with respect to the base case reference process.

- EPP issuing.

This phase starts with the submission of an EPP, and ends with the definition of the updated payment terms, given that the two parties have come to an agreement. After the supplier has uploaded a generic invoice, one party has the possibility to propose an EPP. Given that DD is a buyer-centric programme, it is assumed that it is always the buyer who submits the EPPs. A modification in this sense would clearly affect the process described, but not the assessment of the differential profits, which do not depend on the party that submit the EPP. Therefore, after the buyer submits an EPP, the supplier can accept it. In case the supplier refuses, the buyer has the possibility to submit an updated EPP, presumably with a more appealing discount or with an earlier settlement date. This sub-process continues until either an EPP is accepted or the standard payment terms havebeen reached (i.e. the full amount of the invoice is due). If the supplier agrees on an EPP, the terms of the invoice are updated, and the invoice is ready to be archived.

- Invoice archiving.

Invoice archiving is triggered by three events: the agreement upon an EPP (and the consequent update of the invoice terms), the reaching of contractual payment terms, or mandatory archiving dictated by specific regulations (e.g. 15 days after invoice receiving). If the buyer is not willing to submit any EPP, the system lists the invoice among the ones available for an EPP until either one of the other two events have been reached, and then automatically triggers the archiving process.

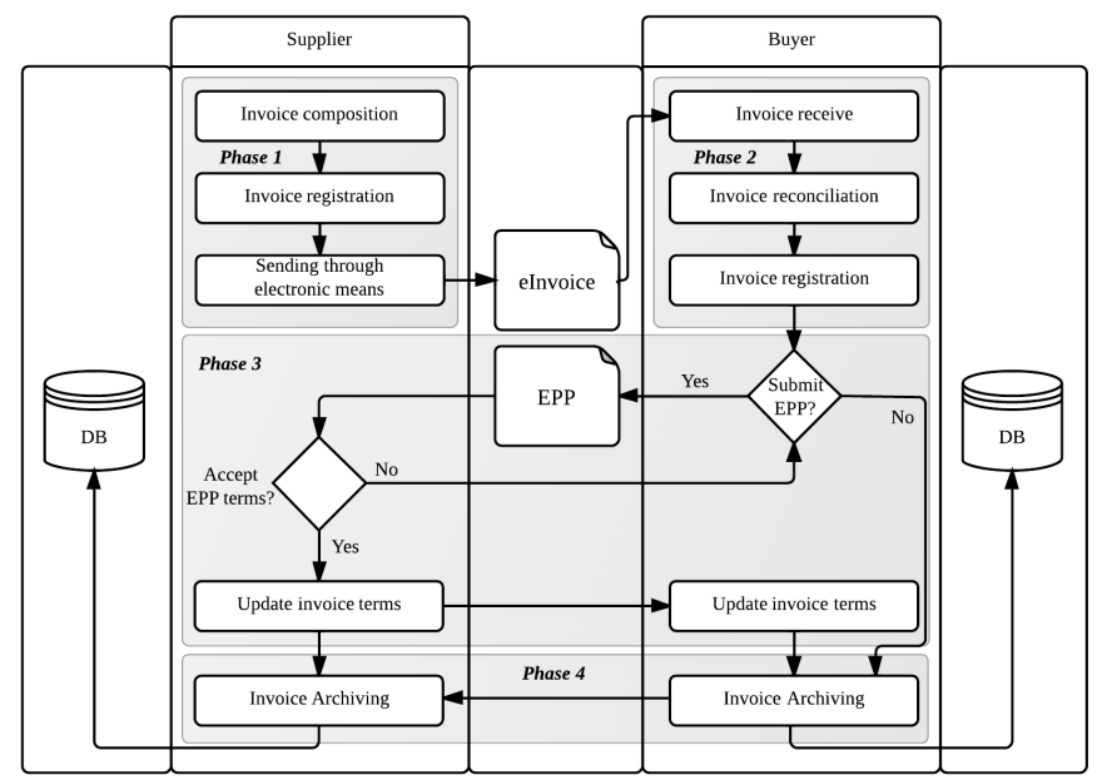

Figure 3. The Dynamic discounting reference process

It is worth to notice that, without significant modification on the reference process, the DD programme can assume two different configurations, based on the role adopted by the service provider. In the first configuration, the service provider develops, provides, and maintains the IT platform for the DD solution, having the buyer financing early payments with its own funds (either available liquidity from operating activities or liquidity provided by a financial third party). In the second configuration, the service provider offers, together with the IT platform, financial resources for the buyer to finance early payments to suppliers. Therefore, in the second configuration, the service provider assumes both an IT and a financial service provider role. In the proposed model the first configuration is taken into account.

\section{THE PROPOSED MODEL}

\section{A. Inputs and Assumptions}

The supply chain is composed by a single buyer and $\mathrm{N}$ suppliers. The suppliers are assumed to be smaller in size with respect to the buyer and indistinguishable from each other. It is also assumed that the buyer is trustworthier than the suppliers (i.e. the buyer has a better credit rating) and therefore it incurs in a lower risk premium than the suppliers. Specifically, $r_{s}$ is the cost for the suppliers of financing one unit of cash for one day (e.g. the daily cost of a form of short term debt comparable with trade credit, such as invoice discounting). Withregard to the buyer, it can access short-term debt (similarly to the suppliers), with a cost of $r_{b}$ per unit of cash per day, or it can use its own liquidity (e.g. generated from operating activities). 
Given the abovementioned assumption, it derives that $r_{b}<r_{s}$.

When the buyer decides to use the DD programme, it sets up the amount of liquidity, equal to liq, available to early pay invoices. Each supplier sells goods to the buyer and issue one invoice every $\mathrm{T}$ days. A period of $\mathrm{T}$ days is called an invoice cycle. Each invoice issued has $G$ days of standard payment terms. Invoices issued at $t=1$ are paid at $t=G$, with $t \in \mathbb{N}[1 ; G]$. In seek of simplicity, a year is modelled to have 12 months of 30 days each.

By construction all the suppliers are similar. Therefore, within an invoice cycle, all the invoices have the same nominal value (i.e. how much the buyer has to pay to the supplier in standard conditions), $v(n)$, for every supplier. This is conceptually equivalent to consider the average value of invoices in each invoice cycle for real cases, in which $v(n)$ varies from one supplier to another. The total nominal value of invoices in an invoice cycle can be defined as $N V(n)=N \cdot v(n)$. Consequently, each instant $t$ there are $G / T$ "active" invoice cycles, for a total of $N \cdot G / T$ invoice waited to be paid. There are $360 / T$ cycles in a year.

\section{B. The Dynamic Discounting Programme}

With a DD programme in place, invoices can be settled dynamically before the $G$ days of payment terms have elapsed. This generates an economic gain for the buyer, equal to the economic loss incurred by the suppliers. Moreover, the buyer sustains a financial cost, due to the financing of the early payment, whereas each of the suppliers has a financial gain. The expected profit of the buyer is:

$$
\pi_{b}=\text { Discounts }- \text { Financial costs }
$$

On the other side, the suppliers have the following expected profit:

$$
\pi_{s}=\text { Financial savings }- \text { Discounts }
$$

When the buyer and a supplier agree upon an EPP, they define a daily discount (i.e. the discount on the nominal value per day of advance) and the "early period" (how much in advance with respect to $G$ days the invoice have to be settled). Supposing that the invoice is paid the same day in which the EPP is accepted, the early period is equal to:

$$
\operatorname{ep}(t)=G-t
$$

While the daily discount is equal to $d d(n, t)$. If an EPP is accepted at time $t$, the buyer will pay to the supplier a discounted value $d v(n, t)$ :

$$
d v(n, t)=v(n) \cdot(1-d d(n, t) \cdot e p(t))
$$

Within an invoice cycle, then, the buyer will have the possibility to early pay invoices to a maximum of $N V(n) \cdot(1-d d(n, t) \cdot e p(t))$, depending on: (i) availability of funding; (ii) ability to find a mutually satisfying discount rate with the supplier.

It is possible to define $\theta(n, t)$ as the percentage of $\mathrm{NV}(\mathrm{n})$ which is available for payment at time $t$ of invoice cycle $n .{ }^{1}$ In seek of simplicity, in this model it is assumed that an EPP is issued as soon as an invoice is eligible for it, and that the same invoice is settled immediately after the EPP has been issued. Thus, $\theta(n, t) \cdot N V(n)$ represents the nominal value of invoices paid by the buyer at time $t$ of invoice cycle $n$. The yearly revenues of the buyer (which coincide with the additional economic cost for the suppliers) can be defined as:

$$
\text { Discounts }=\sum_{n=1}^{\frac{360}{T}} \sum_{t=1}^{G} \theta(n, t) \cdot N V(n) \cdot d d(n, t) \cdot \operatorname{ep}(t)
$$

As stated before, the buyer bears a financial cost to finance the early payment, while the supplier has a financial gain due to an anticipated income. For a generic invoice settled $e p(t)$ days earlier with respect to contractual terms, the financial saving for the supplier is defined as:

$$
f s(n, t)=d v(n, t) \cdot r_{s} \cdot e p(t)
$$

Defining the Discounted Nominal Value (i.e. the cash flow in for the suppliers) as $D N V(n, t)=\theta(n, t)$. $N V(n) \cdot(1-d d(n, t) \cdot e p(t))$, the overall yearly financial saving for all the suppliers is defined as:

$$
\text { Financial Saving }=r_{s} \cdot \sum_{n=1}^{\frac{360}{T}} \sum_{t=1}^{G} D N V(n, t) \cdot \operatorname{ep}(t)
$$

The financial cost sustained by the buyer depends instead on the typology of funds it is using.

As stated above, the buyer "assigns" an amount of liquidity (liq) to the programme. This amount is assumed to be "assigned" at the beginning of the year, and cannot be used in any alternative investment. Although this assumption might seem restrictive, its effect on the outcome of the model is somehow trivial.In fact, in absence of seasonality (i.e. when $v(n)$ is constant through the different cycles), the maximum (reasonable) value of liq equals the value of invoices of one single invoice cycle: the choice to set up this amount of liquidity at the beginning of the year is the most reasonable. Assuming to have set liq to its maximum value at the beginning of a generic invoice cycle $n$, the funds that (without the DD programme) should have been used to settle invoices of cycle $n$ become available to treasury when standard payment terms expire (i.e. $G$ days later).However, given that liquidity is already available, these funds are unnecessary:either invoices of cycle $n$ have been settled early, or they will be settled on standard payment terms using the remaining part of liq. Therefore, these funds (equal to $l i q$ ) will become automatically available to early settle invoices of cycle $n+1$, and so forth. Therefore, a value of liqhigher than the value of nominal invoices of a single invoice cycle is not reasonable. Liquidity has a fixed annual cost $\left(y_{l}\right)$, equal to the yield of an alternative

\footnotetext{
${ }^{1} \theta(n, t) \cdot N V(n)$ represents the value of invoices which are eligible for an EPP, i.e. which, referring to Fig. 3, have been issued and sent by the supplier and received and correctly reconciliated by the buyer.
} 
investment, which can be considered sunk. This implies that once liquidity has been assigned to the DD programme, it is always more convenient to use it in place of short-term debt.

The financial charges in case in which the supplier uses its own liquidity to settle an invoice is equal to $d v(n, t) \cdot r_{s} \cdot \operatorname{ep}(t)$.Such financial cost is paid only when liquidity (which is a sunk cost) is not available. Defining $\operatorname{al}(n, t)$ as the difference between liquidity available and the value of invoices of cycle $n$ already discounted at time $t$ :

$$
a l(n, t)=l i q-\sum_{m=1}^{t-1} d v(n, m)
$$

The financial cost can be calculated as:

$$
\begin{aligned}
& f c(n, t) \\
& = \begin{cases}0 & \text { if al }(n, t)-d v(n, t) \geq 0 \\
d v(n, t) \cdot r_{b} \cdot e p(n, t) & \text { otherwise }\end{cases}
\end{aligned}
$$

The overall yearly financial cost equals:

$$
\text { Financial Cost }=\sum_{n=1}^{\frac{360}{T}} \sum_{t=1}^{G} f c(n, t)+l i q \cdot y_{l}
$$

\section{The Discount Rate}

One of the most critical aspects of the DD programme is the discount rate. Although the actual value might heavily depend on negotiation and contractual power issues, it is still possible to derive some considerations on it. Assuming that the buyer is using short-term debt only, it is possible to derive the minimum condition on $d d$ for which the buyer is willing to early pay an invoice (see appendix $\mathrm{A})^{2}$ :

$$
d d_{\min }=\frac{r_{b}}{1+e p \cdot r_{b}}
$$

On the same line of reasoning, maximum condition on $d d$ for the supplier can be derived as well (see appendix A):

$$
d d_{\text {max }}=\frac{r_{s}}{1+e p \cdot r_{s}}
$$

From these conditions it is possible to infer that:

a) The higher the delta between $r_{b}$ and $r_{s}$, the wider the "space" for negotiation between the buyer and the supplier;

b) The earlier the payment, the wider the "space" for negotiation between the buyer and the supplier;

c) The use of liquidity from the buyer plays an important role; being its cost sunk, every invoice early settled through liquidity has, virtually, no minimum discount rate.

It is worth to notice that, in practical applications, a supplier might accept a discount higher than $d d_{\text {max }}$. It is not uncommon, in countries where two-party trade credit policies are widely used, to accept discount in the area of $2 \%$ for an early period of 20 days, even by highly trustworthy firms [16]. This is due to different reasons.

\footnotetext{
${ }^{2}$ simplifying, $e p(t)=e p$
}

For example, risk on the specific transaction might exist: if the supplier is sufficiently risk-adverse, it might accept a higher discount.

The considerations described above support claims in literature that the adoption domain of DD requires cashrich, highly trustworthy anchor buyers and SMEs [22]. In fact, the trustworthiness of the buyer, compared with the typical low credit standing of SMEs, determines a high difference between $r_{b}$ and $r_{s}$. Moreover, being cash-rich there is a higher probability that the buyer will have liquidity available to fund the programme, further increasing the possibility of finding a discount rate that will satisfy both parties.

\section{CASE STUdY}

In this section, the model is applied to a real-world case study. The case wants to contextualize the model in a plausible scenario. Data for input and contextual variables have been gathered from interviews, analysis of secondary sources or educated guesses from domain experts.

\section{A. Context}

The model is applied to the case of company $\mathrm{ABC}$, a leading retailer in the consumer goods industry in Italy.Although ABC has more than 6,000 suppliers, only 300 are connected through its Electronic Data Interchange (EDI) platform and consequently are able to exchange electronic orders and invoices with ABC. However, as represented in Fig. 4, these 300 suppliers account for $50 \%$ of $\mathrm{ABC}$ annual purchases, for a total value of invoices exchanged of around 1 billion $€$.

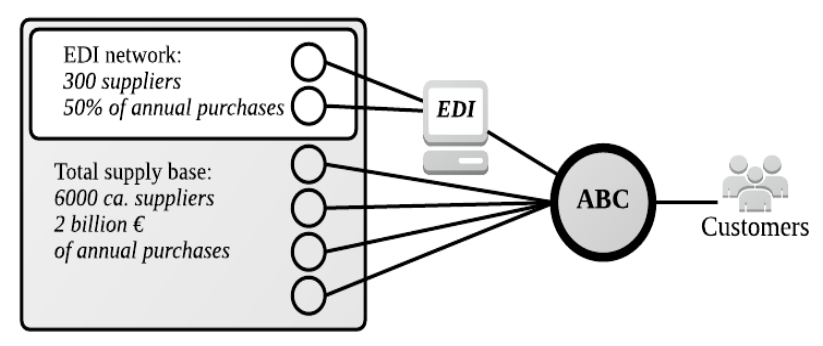

Figure 4. ABC's supply chain

To conservatively take into account contingent factors that may negatively affect the adoption of the DD programme (e.g. largest suppliers unwilling to join the program, inefficiencies in the suppliers onboarding process) the starting values for the number of suppliers involvedis set to 200 while the total value of annual purchase of $\mathrm{ABC}$ interested by the DD programme is set to 500 million $€$.

\section{B. Inputs and Other Contextual Variables}

Table I illustrates the value assumed by the different parameters required to run the model. Data gathered shows that $\mathrm{ABC}$ issue invoices once per month (i.e. $\mathrm{T}=30$ ), and that a reliable estimation of its payment terms 
can be 90 days (i.e. $\mathrm{G}=90$ ). $\mathrm{ABC}$ is considered cash-rich (which is reasonable, given its negative cash conversion cycle), and thus the liquidity allocated to the program has initially been set as the maximum value possible, and its cost has been set as the current Euribor rate at 12 months.

TABLE I. VALUE ASSUMED By THE DIFFERENT PARAMETERS

\begin{tabular}{ll}
\hline Parameter & Value assumed \\
\hline $\mathrm{T}$ & 30 days \\
$\mathrm{G}$ & 90 days \\
$\mathrm{v}(\mathrm{n})$ & $208,333 €($ for each $n)$ \\
$\mathrm{N}$ & 200 \\
$\boldsymbol{r}_{\boldsymbol{b}}$ & $0.0056 \%(2 \%$ yearly) \\
$\boldsymbol{r}_{\boldsymbol{s}}$ & $0.0278 \%(10 \%$ yearly) \\
$\mathrm{liq}$ & $41,666,667 €$ \\
$\mathrm{y}_{1}$ & $0,34 \%$ (yearly) \\
$\theta(\mathrm{n}, \mathrm{t})$ & $1 / \mathrm{G}=1,1 \%$ \\
\hline
\end{tabular}

The daily discount (assumed constant throughout the year), has been set equal to $0.014 \%$, in order to divide (a posteriori) profits in two equal shares between the buyer and the suppliers. However, given the criticality of the parameter, a sensitivity analysis has been performed on it.

Table II reports the results of the application of the DD programme.

TABLE II. RESULTS OF THE NUMERIC EXAMPLE

\begin{tabular}{ll}
\hline Variable & Result \\
\hline Discounts (buyer) & $3,203,710 € /$ year \\
Financial Costs & $141,667 € /$ year \\
$\begin{array}{l}\text { Discounts (single supplier) } \\
\text { Discounts (all suppliers) }\end{array}$ & $16,019 € /$ year \\
$\begin{array}{l}\text { Financial Savings } \\
\text { (single supplier) }\end{array}$ & $3,203,710 € /$ year \\
$\begin{array}{l}\text { Financial Savings } \\
\text { (all suppliers) }\end{array}$ & $31,329 € /$ year \\
$\pi($ buyer) & \\
$\pi($ per single supplier) & $6,265,753 € /$ year \\
$\pi$ (suppliers) & $3,062,043 € /$ year \\
\hline
\end{tabular}

\section{Sensitivity Analysis}

A sensitivity analysis has been performed on two of the most critical parameters: the daily discount and the value of liquidity used by the buyer.

TABLE III. SENSITIVITY ANALYSIS ON THE Discount RATE

\begin{tabular}{lll}
\hline $\mathrm{dd}$ & $\pi$ (buyer) [€/y] & $\pi$ (suppliers) [€/y] \\
\hline $0,0273 \%$ & 6073614 & 0 \\
$0,0244 \%$ & 5400722 & 684170 \\
$0,0214 \%$ & 4727830 & 1368339 \\
$0,0184 \%$ & 4054937 & 2052509 \\
$0,0155 \%$ & 3382045 & 2736678 \\
$0,0125 \%$ & 2709153 & 3420848 \\
$0,0096 \%$ & 2036260 & 4105017 \\
$0,0066 \%$ & 1363368 & 4789187 \\
$0,0037 \%$ & 690476 & 5473356 \\
$0,0007 \%$ & 17583 & 6223064 \\
\hline
\end{tabular}

The sensitivity analysis on discount rate, presented in Table III, shows that, under the assumption of this case study, the profits are fairly linear with respect to the value of the daily discount.

On the other side, there is a non-linear (quadratic) relationship between the parameter liq and the benefits for the buyer, as showed in Fig. 5. This quadratic relationship is due to the fact that there is a lower bound on ep, under which it is more convenient to finance an early payment with short term debt.

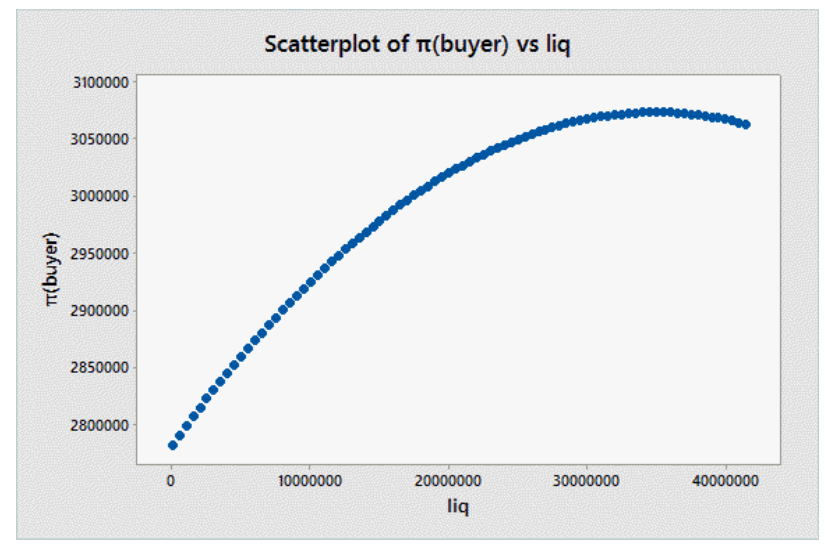

Figure 5. Scatterplot of buyer profit vs. liq

Under the assumption of this case study, it is possible to estimate this threshold. It is more convenient to finance an invoice through short term debt if this equation holds:

$$
d n v(n, t) \cdot r_{b} \cdot \operatorname{ep}(t)<d n v(n, t) \cdot y_{l} \cdot \frac{G}{360}
$$

where the first term is the cost of financing an invoice through short-term debt and the second term is the cost of financing an invoice through the company own liquidity. Solving for ep:

$$
e p(t)<\frac{y_{l} \cdot G}{360 \cdot r_{b}}
$$

In the case study, the threshold is equal to 15,3 days. In fact, the maximum of the curve showed in Fig. 5 occurs exactly when the parameter $l i q$ is set to cover a value equal to the $83 \%$ of the value of the invoices of an invoice cycle, which, considering $\theta=1 / G$, equals paying invoices with liquidity until ep is higher than 15 days. This evidence should be taken into consideration while deciding the amount of liquidity to be used in the programme.

\section{EFFECTS ON NET OPERATING WORKING CAPITAL}

Although the overall benefits may seem risible, the DD programme can greatly influence the cash conversion cycle of players involved and consequently their net operating working capital (NOWC). Clearly, the supplier benefits from a NOWC reduction, while the buyer suffers an increase in its NOWC. With regard to the supplier, depending on characteristics of the company such as value of account payables and length of the production cycle, its NOWC can even halve if the DD programme is used on all of its account receivables. This improvement 
in the NOWC can be the motivation for the suppliers to the programme, even leading to discounts rates which profit-wise are systematically more favourable to the buyer (as it is common in traditional two-part trade credit). The corresponding negative effect on the buyer NOWC can have different impacts depending on the buyer characteristics. Again, in line with existing literature, a cash-rich buyer will be more willing to join the program, because the increase of NOWC will have relatively less negative impact with respect to cashconstrained companies. As an example, a buyer such as $\mathrm{ABC}$, which has a negative cash conversion cycle but operates in an industry typically known for reduced economic margin, can easily compensate the negative effect on the NOWC with the improvement of its economic margin driven by the discounts.

\section{CONCLUSIONS}

This paper proposes a model for assessing the tangible benefits of the application of DD in a supply chain. The paper defines both the generic process for the DD and the analytical model developed. In the last section, a case study and a sensitivity analysis have been presented. The main limitations of this paper are related to the basic assumption of the model: some of them might be relaxed to derive a more holistic mathematical interpretation of the solution, which could lead to more interesting results. Specifically, further research should focus on two main aspects: (i) deterministic demand and absence of risk on invoices should be relaxed in favour of stochastic demand and non-zero default probabilities; (ii) negotiation should be introduced, relaxing the assumption that invoices are settled once they are eligible for an EPP. Finally, the model should be tested in a real-world scenario.

\section{APPENDIX A. MAXIMUM AND MINIMUM CONDITIONS ON DD}

With reference to a single invoice, the minimum condition on $d d$ can be defined calculating the minimum value of $d d$ for which the benefit for the supplier (the financial saving) is higher than the economic loss (the discounted granted). Neglecting the subscripts $n$ and $t$, it results:

$$
\begin{gathered}
v \cdot(1-d d \cdot e p) \cdot r_{s} \cdot e p-v \cdot d d \cdot e p \geq 0 \\
d d \cdot e p \cdot\left(r_{s} \cdot e p+1\right) \geq r_{s} \cdot e p \\
d d \geq \frac{r_{s}}{\left(1+r_{s} \cdot e p\right)}=d d_{\min }
\end{gathered}
$$

On the same line of reasoning, the maximum condition on $d d$ is defined calculating the maximum value of $d d$ for which the benefit for the buyer (the discount) is higher than the financial cost:

$$
\begin{gathered}
v \cdot d d \cdot e p-v \cdot(1-d d \cdot e p) \cdot r_{b} \cdot e p \geq 0 \\
d d \cdot e p \cdot\left(-r_{b} \cdot e p-1\right) \geq r_{b} \cdot e p \\
d d \leq \frac{r_{b}}{\left(1+r_{b} \cdot e p\right)}=d d_{\max }
\end{gathered}
$$

\section{REFERENCES}

[1] V. Ivashina and D. Scharfstein, "Bank lending during the financial crisis of 2008," J. Financ. Econ., vol. 97, no. 3, pp. 319-338, Sep. 2010.

[2] E. Garcia-Appendini and J. Montoriol-Garriga, "Firms as liquidity providers: Evidence from the 2007-2008 financial crisis," $J$. Financ. Econ., vol. 109, no. 1, pp. 272-291, July 2013.

[3] B. Coulibaly, H. Sapriza, and A. Zlate, "Financial frictions, trade credit, and the 2008-09 global financial crisis," Int. Rev. Econ. Finance, vol. 26, pp. 25-38, Apr. 2013.

[4] P. Polak, R. Sirpal, and M. Hamdan, "Post-crisis emerging role of the treasurer," Eur. J. Sci. Res., vol. 86, no. 3, pp. 319-339, 2012.

[5] E. Hofmann, "Supply chain finance-some conceptual insights," Logist. Manag. Innov. Logistikkonzepte Wiesb. Dtsch. Univ.-Verl., pp. 203-214, 2005.

[6] E. Camerinelli, "Supply chain finance," J. Paym. Strategy Syst., vol. 3, no. 2, pp. 114-128, 2009.

[7] J. F. Lamoureux and T. A. Evans, "Supply chain finance: A new means to support the competitiveness and resilience of global value chains," Social Science Research Network, Rochester, NY, Oct. 2011.

[8] D. A. Wuttke, C. Blome, and M. Henke, "Focusing the financial flow of supply chains: An empirical investigation of financial supply chain management," Int. J. Prod. Econ., vol. 145, no. 2, pp. 773-789, Oct. 2013.

[9] W. S. Randall and M. T. Farris II, "Supply chain financing: Using cash-to-cash variables to strengthen the supply chain," Int. J. Phys. Distrib. Logist. Manag., vol. 39, no. 8, pp. 669-689, 2009.

[10] P. Polak, "Addressing the post-crisis challenges in working capital management," Int. J. Res. Manag., vol. 6, no. 2, 2012.

[11] X. Chen and C. Hu, "The value of supply chain finance," in Supply Chain Management-Applications and Simulations, In Tech, 2011, pp. 111-132.

[12] H. C. Pfohl and M. Gomm, "Supply chain finance: Optimizing financial flows in supply chains," Logist. Res., vol. 1, no. 3, pp. 149-161, 2009.

[13] M. L. Gomm, "Supply chain finance: Applying finance theory to supply chain management to enhance finance in supply chains," Int. J. Logist. Res. Appl., vol. 13, no. 2, pp. 133-142, 2010.

[14] S. Templar, M. Cosse, E. Camerinelli, and C. Findlay, "An investigation into current supply chain finance practices in business: A case study approach," in Proc. The Logistics Research Network (LRN) Conference, Cranfield (UK), 2012.

[15] R. Mangiaracina, M. Melacini, and A. Perego, "A critical analysis of vendor managed inventory in the grocery supply chain," Int. J. Integr. Supply Manag., vol. 7, no. 1-2, pp. 138-166, Dec. 2012.

[16] C. H. Lee and B. D. Rhee, "Trade credit for supply chain coordination," Eur. J. Oper. Res., 2011.

[17] C. T. Chang, J. T. Teng, and S. K. Goyal, "Inventory lot-size models under trade credits: A review," Asia-Pac. J. Oper. Res., vol. 25, no. 1, pp. 89-112, 2008.

[18] D. Seifert, R. W. Seifert, and M. Protopappa-Sieke, "A review of trade credit literature: Opportunities for research in operations," Eur. J. Oper. Res., vol. 231, no. 2, pp. 245-256, Dec. 2013.

[19] H. Soni, N. H. Shah, and C. K. Jaggi, "Inventory models and trade credit: a review," Control Cybern., vol. 39, no. 3, pp. 867-882, 2010.

[20] P. Basu and S. K. Nair, "Supply chain finance enabled early pay: Unlocking trapped value in B2B logistics," Int. J. Logist. Syst. Manag., vol. 12, no. 3, pp. 334-353, Jan. 2012.

[21] L. F. Klapper and D. Randall, "Financial crisis and supply-chain financing," Trade Finance Gt. Trade Collapse, pp. 73, 2011.

[22] J. J. Nienhuis, M. Cortet, and D. Lycklama, "Real-time financing: Extending e-invoicing to real-time SME financing," J. Paym. Strategy Syst., vol. 7, no. 3, pp. 232-245, 2013.

[23] GBI, "Vendor position grid-2013 working capital technology guide," Global Business Intelligence, 2013.

[24] The Paypers, "E-Invoicing, supply chain finance \& e-billing market guide 2014," June 2014.

[25] D. Gupta and L. Wang, "A stochastic inventory model with trade credit," Manuf. Serv. Oper. Manag, vol. 11, no. 1, pp. 4-18, Jan. 2008.

[26] L. N. De and A. Goswami, "Probabilistic EOQ model for deteriorating items under trade credit financing," Int. J. Syst. Sci., vol. 40, no. 4, pp. 335-346, 2009. 
[27] A. Perego and A. Salgaro, "Assessing the benefits of B2B trade cycle integration: a model in the home appliances industry," Benchmarking Int. J., vol. 17, no. 4, pp. 616-631, Jul. 2010.

Luca M. Gelsomino is a PhD candidate at Politecnico di Milano, in the Department of Management, Economics and Industrial Engineering, where he gives lecture on Logistics and Supply Chain Management. He is a researcher within the Supply Chain Finance Observatory of the Politecnico di Milano School of Management. Luca Gelsomino is the corresponding author: lucamattia.gelsomino@polimi.it.

Alessandro Perego is Full Professor of Logistics and Supply Chain Management at Politecnico di Milano, where he chairs the course of Logistics and Production Systems Management and Logistics Management. During his career he chaired also the courses eOperations and Industrial Logistics. He is the co-founder and member of the Scientific Board of the Observatories Digital Innovation of the School of Management of Politecnico di Milano, as well as the responsible of the Observatories on Supply Chain Finance, Contract Logistics, Digital Agenda, eBusiness B2b, eCommerce B2c, Electronic Invoicing and Dematerialization, Internet of Things, Mobile Payment \& Commerce, and Mobile Wireless and Business. He is also the director of the IoT $\mathrm{Lab}$ of Politecnico di Milano.

Riccardo Mangiaracina is an Assistant Professor at Politecnico di Milano, where he holds thechairs of Production Plants and Mechanical Plants and where he gives lectures on Logistics andSupply Chain Management. He gained his PhD at Politecnico di Milano, Department ofManagement, Economics and Industrial Engineering in 2007. He is a member of the MIP'sfaculty and he is the Research Director of the B2C eCommerce Observatory of Politecnico diMilano.

Angela TuminoPhd, is an Assistant Professor at the Department of Management, Economics and Industrial Engineering of Politecnico di Milano, where she holds the chair of Logistics and Production Systems Management. She is the Research Director of the Internet of Things Observatory of Politecnico di Milano School of Management. 